\title{
Immune modulation promoted by probiotic fermented milk in the mucosal immune system in an experimental model of allergy
}

\author{
E. Velez ${ }^{1}$, C. Maldonado ${ }^{1,2}$, E. Carmuega ${ }^{3}$, R. Weil ${ }^{4}$ and G. Perdigón ${ }^{1,2}$ \\ ${ }^{1}$ Centro de Referencia para Lactobacilos (CERELA), Tucumán, Argentina, ${ }^{2}$ Cátedra de Inmunología, Instituto \\ de Microbiología Luis C. Verna, Facultad de Bioquímica, Química y Farmacia, UNT, Argentina, ${ }^{3}$ Nutritia, Bs. As., \\ Argentina and ${ }^{4}$ Departamento de investigación y desarrollo, DANONE, Argentina S.A., Bs. As., Argentina
}

Intestinal microbiota has an essential role in the maturation and function of the immune system. Changes in the microbiota, together with genetic factors induce the development of allergy with a typical Th2 profile ${ }^{(1)}$. Several studies have shown that probiotics have a beneficial effect in disease and can stimulate the mucosal immune system by improving microbiota composition ${ }^{(2)}$; hence, probiotics oral administration is proposed to avoid the allergy development by balancing microbiota and modulating the immune system, not only at the intestinal mucosa, but also in other mucosal sites and at systemic level ${ }^{(3)}$. This study was aimed to evaluate the adjuvant immune effect of the oral administration of a probiotic fermented milk (PFM) in the intestinal mucosa and the extent of these effects on distant mucosal sites (bronchus) in an experimental mouse model of allergic airway reactivity to ovoalbumin (OVA). Experimental groups: normal-control (NC), Basal (B-5days-PFM); OVA-Sensitization-control (SC), Previous (P) (5d-PFM+OVA+H2O) and Continuous (C) (5d$\mathrm{PFM}+\mathrm{OVA}+\mathrm{PFM}) . \mathrm{SC}, \mathrm{P}$ and $\mathrm{C}$ were sensitized with OVA $1 \%$ followed by daily exposures to OVA aerosols. At 7 and 15 days postsensitization (dPS) specific-IgE, specific-IgG and IL-10 in serum, total S-IgA, IL-10 and IFN- $\gamma$ in intestinal fluid (IF), specific-IgE in bronchoalveolar lavage (BAL) were determined by ELISA. The number of IgA +, IL-10 + and IL-4 + cells in the lamina propria of small intestine (SI) and lungs were determined by immunofluorescense assay. In large intestine (LI) total populations of total anaerobes, lactobacilli, bifidobacteria and enterobacteria in selective media were determined. Specific-IgE was reduced in treated groups with regard to $\mathrm{SC}$ in serum and BAL (DO 450nm) (Table 1). Specific-IgG increased in all groups but showed the highest values in $\mathrm{C}$ (Table 2).

\begin{tabular}{lccccc} 
Table 1. Anti OVA IgE in serum (Absorbance, DO $450 \mathrm{~nm})($ media $\pm \mathrm{SD})$ \\
\hline \multicolumn{7}{c}{ NC } & B & SC & P & C \\
\hline 5 dPFM & $0.08 \pm 0.01$ & $0.09 \pm 0.01$ & & & \\
7 dPS & & & $0.87 \pm 0.07$ & $0.38 \pm 0.13$ & $0.38 \pm 0.012$ \\
$15 \mathrm{dPS}$ & & $0.47 \pm 0.02$ & $0.47 \pm 0.01$ & $0.31 \pm 0.06$ \\
\hline
\end{tabular}

Table 2. Anti OVA IgG in serum (Absorbance, DO $450 \mathrm{~nm})($ media \pm SD)

\begin{tabular}{lccccr}
\hline & NC & B & SC & P & C \\
\hline 5 dPFM & $0.06 \pm 0.01$ & $0.08 \pm 0.03$ & & & \\
$7 \mathrm{dPS}$ & & & $0.78 \pm 0.01$ & $0.80 \pm 0.05$ & $1,03 \pm 0.07$ \\
$15 \mathrm{dPS}$ & & & $0.67 \pm 0.06$ & $0.65 \pm 0.13$ & $0.92 \pm 0.10$ \\
\hline
\end{tabular}

IL-10 values increased in SC in SI fluid compared to treated groups, with no changes in serum. Total S-IgA from SI fluid significantly increased in CS and P compared to NC, B and C. IL-4 + cells increased significantly in SC in lungs compared to the other groups at 7 and $15 \mathrm{dPS}$; in SI no differences were found between controls and treated groups. The number of IL-10+ cells was significantly higher in the lamina propria of SI from SC group compared to P and C at 7 and $15 \mathrm{dPS}$. PFM induced a decrease of enterobacteria and increase of bifidobacteria only in $\mathrm{C}$, other populations were not affected. PFM reduced specific-IgE levels in serum and BAL in mice with continuous treatment; this could be mediated by intestinal microbiota regulation that might have influence on the expression of cytokines IL-4 (Th2 type) and IL-10 (regulatory cytokine) at the mucosal level (intestine and lungs). However systemic and mucosal normal immune response was not affected because IgG and S-IgA production was not altered by IL-10.

1. Bjorksten B, Sepp E, Julge K et al. (2001) J Allergy Clin Immunol 108, 516-520.

2. Galdeano CM \& Perdigon G (2006) Clin Vaccine Immunol 13, 219-226.

3. de Moreno de LeBlanc A, Maldonado Galdeano C, Chaves, S and Perdigon, G. (2005) Eur J Inflamm 3, 25-30. 